\title{
Association Between Obesity, White Blood Cell and Platelet Count
}

\author{
Leila Jamshidi, ${ }^{1, *}$ and Asghar Seif ${ }^{2}$ \\ ${ }^{1}$ Department of Nursing, Faculty of Basic Science, Hamedan Branch, Islamic Azad University, Hamedan, Iran \\ ${ }^{2}$ Department of Statistics, Bu-Ali Sina University, Hamedan, Iran \\ "Corresponding author: Leila Jamshidi, Department of Nursing, Faculty of Basic Science, Hamedan Branch, Islamic Azad University, Hamedan, Iran. E-mail: \\ jamshidi.leila@gmail.com
}

Received 2015 December 05; Revised 2016 May 13; Accepted 2017 January 09.

\begin{abstract}
Background: Cardiovascular disease is resulted from malfunctioning's of heart as well as blood vessels. More than two decades ago it was noted that the number of white blood cells can be an indicated of the existence of such disease. Platelet activation and aggregation are among the include processes. That are considered in pathophysiology of a coronary heart disease. However there seems to be a paucity of research on platelet count in patients suffering from obesity. Moreover although previous studies have indicated a positive correlation between platelet and white blood cells. Counts and mortality from coronary heath disease, how this might correlate with obesity is an issue still in need of more attention.

Objectives: The present study was designed to evaluate platelet count and white blood cell count in those patients who suffer from obesity as compared with control subjects who were not obese.

Methods: In this cross-sectional study, there were a total of 1024 Iranian subjects living in Hamedan include, staff of Islamic Azad University of Hamedan and subjects who referred to Ekbatan hospital in Hamedan during the period of 6 months randomly and staff of Islamic Azad University of Hamedan. The absence of infectious disease was confirmed by a general practitioner. Finally, the samples included 486 subjects, 254 male, and 232were females. Body mass index was calculated. Waist circumference in the Iranian subjects, at least in men $89(\mathrm{~cm})$ and women $91(\mathrm{~cm})$ was considered. White blood cell and platelet count was measured. T-test and Pearson's correlation were run to analyze the collected data through SPSS software version 16.

Results: The average age of the subjects was $34.75 \pm 8.1$ years. The body mass indexes in 7.6 percent of men and 15.7 of women were greater than $30\left(\mathrm{~kg} / \mathrm{m}^{2}\right)$. The averages of waist circumference in men and women was $1.04 \pm 0.5$ and $89.3 \pm 10.2(\mathrm{~cm})$, respectively. Also there seemed to be a significant correlation between waist circumstance and the number of platelets in both male and female subjects $(\mathrm{P}<0.0001)$; however, only in overweight $(\mathrm{P}=0.005)$, and obese women $(\mathrm{P}<0.0001)$. The platelet counts increased significantly. Furthermore, there was a positive correlation between BMI and WBC in the obese group $(\mathrm{P}<0.05)$.

Conclusions: Our results showed a relationship between central and general adiposity and WBC count as an inflammation factor, and higher count of platelets count in subjects.
\end{abstract}

Keywords: Obesity, White Blood Cell, Platelet Count

\section{Background}

Nowadays, humans are threatened by four major noncommunicable diseases (NCDs). Disease including diabetes, cancers, cardiovascular disease and respiratory disease, and as statistics show. These four disease account for 35 million annual deaths around the globe $80 \%$ of which generally happens in low and middle income countries [1, 2]. However notable fact is that a large percentage of such disease, about $80 \%$ to be precise can be prevented just by eliminating common risk factors such as tobacco use, poor diet, alcohol consumption and physical inactivity, and specially a byproduct of modern inactive life style, that is obesity [3].

Malfunctioning's of the heart and blood vessels result in conditions such as heart attacks, strokes, hypertension or increased blood pressure, peripheral artery disease, rheumatic heart disease, congenital heart disease and many finally lead to heart failure [4]. Morbidity estimates from such cardiovascular disease normally known as CVDs is higher than any other death cause in human beings around the globe. The death tolls from these disease in 2012, for example, accounted for 31\% (around 17.5 million deaths) of all the deaths in the world, among which an estimated 7.4 million death were caused by coronary disease and around 6.7 million deaths were caused by strokes. The other related statistics are also embarrassing. For instance among the Non-communicable disease taking mortalities in people under the age of 70, CVDs account for an annual 16 million deaths out of which $82 \%$ are normally reported in low and middle- income countries. However, it is possible to prevent most of these disease through nationwide campaigns that address behavioral risk factors such as tobacco use, poor diet, obesity, lack of physical activity, alcohol consumption.

People suffering such disease and even those at risk 
groups suffering from condition such as hypertension, diabetes or hyperlipidemia are in need of counseling, early detection and medical tests and prescriptions [5].

An association between white blood cell (WBC) count and cardiovascular disease was first noted more than a quarter of a century ago. It is now appreciated that inflammation plays a central role in atherosclerosis and acute coronary syndromes (ACS) [6]. Several epidemiological studies have consistently demonstrated a significant relationship between white blood cell count (WBC) and the occurrence of coronary heart disease and stroke [7].

Infection and inflammation may contribute and promote to vascular endothelial layer accelerate the development of atherosclerosis. Inflammation may also promote atherosclerotic plaque rupture and thrombosis. White blood cells may serve as an important biomarker for these disease processes. Elevated WBC may also be a risk factor for acute myocardial infarction, coronary artery disease, coronary heart disease (CHD), and stroke. Studies have also found it to be associated with CHD and all-cause mortality. WBC has also been associated with several cardiovascular disease (CVD) risk factors including serum cholesterol, triglycerides, and tobacco use [8]. The prevalence of obesity has increased dramatically world- wide over the last decades and has now reached epidemic proportions [9].

According to the statistics issued by the world health organization (WHO), obesity has more than doubled in the world in the last three decades, and based on relates reports issued in 2014, from among 109 billion overweight adults over the age 18,600 million were obese. For children is not much different in that in 2013 around 42 million children under 5 were identified and reported as overweight or obese. Raised BMI is a major risk factor for noncommunicable diseases such as: cardiovascular diseases (mainly heart disease and stroke), which were the leading cause of death in 2011; diabetes; musculoskeletal disorders (especially osteoarthritis - a highly disabling degenerative disease of the joints); some cancers (endometrial, breast, and colon) $[9,10]$.

Platelet activation and aggregation are among the main processes. That are normally controlled in the pathophysiology of a coronary heart disease, where mean platelet volume (MPV) is increased in acute myocardial infarction, acute ischemic stroke, preeclampsia and renal artery stenosis.

Importantly, an elevated Mean platelet volume predicts a poor outcome following myocardial infarction, restenosis following coronary angioplasty and the development of preeclampsia. MPV is also elevated in some risk conditions such as hypercholesterolemia, diabetes mellitus and hypertension. Despite of all this, there seems to be a lack of studies specifically addressing MPV in people suf- fering from obesity [11]. Besides, despite positive reported correlations between platelet and white blood cells counts and the occurrence of cardiovascular heart disease, there is a paucity of research on the possible relationship between these measures and obesity as a risk factor for heart disease [11].

\section{Objectives}

The present study was designed to evaluate platelet count and white blood cell count in patients suffering from obesity as compared with those in the control group who do not suffer from this condition.

\section{Methods}

In this cross-sectional study, a total of 1024 Iranian subjects living in Hamedan, include, staff of Islamic Azad University of Hamedan and subjects who referred to Ekbatan hospital in Hamedan during the period of 6 months from March to August 2011 were examined. They were randomly selected. Taking blood samples and questionnaire completion was performed by well-trained nurses. Exclusion criteria for entry into the study were smoking habit, sustained hypertension (systolic blood pressure $140 \mathrm{mmHg}$ and/or diastolic blood pressure $90 \mathrm{mmHg}$ in clinic and daytime ambulatory), diabetes mellitus (fasting glucose $126 \mathrm{mg} / \mathrm{dL}$ or hemoglobin A1c > 6.2\%), hyper cholesterolemia (serum LDL cholesterol $160 \mathrm{mg} / \mathrm{dL}$ ), hyper triglyceridaemia (serum triglyceride $400 \mathrm{mg} / \mathrm{dL}$ ), renal failure (serum creatinine $>$ $1.5 \mathrm{mg} / \mathrm{dL}$ and blood urea nitrogen $>30 \mathrm{mg} / \mathrm{dL}$ ), heart failure, peripheral vascular disease, hematological disorders, acute or chronic infection, cancer and hepatic disease and smokers. Due to history and complete blood cell count and other tests, absence of infectious disease was confirmed by a general practitioner (there were some types of this test in patients' medical records and other required tests, were performed by researchers. Among 1,024 people who referred, only 486 were eligible prior to the study, the participants signed an informed consent form.

The checklist was used to measure instances such as the extent of abdominal obesity (Waist circumference), weight, and height (measuring body mass index), WBC and platelet count. To measure the waist circumstance (the area from the lowest rib to the tip) a plastic meter was used.

The nature of the screening was described to the participants. The anthropometric variables such as weight, height and waist circumference were also measured as described below. In the light of the guidelines described by the National Institutes of Health in 2000, waist circumference was measured by an elastic tape at the top of the iliac 
crest running parallel to the floor at the end of normal expiration.

According to the Tehran Lipid and Glucose Study after following studies over 30 provinces, waist circumference in the Iranian subjects sectional, over at least $89(\mathrm{~cm})$ in men and $91(\mathrm{~cm})$ in women is considered as abdominal obesity [12].

The measurement of weight and height is an objective starting point for the health and nutritional assessment. A clinical assessment beings by anthropometric measurement, namely weight, height, and BMI. This can provide important first clues of a client's nutritional status. Following a BMI determination, terms such as Normal weight, underweight, overweight, and obese are used to describe the client. The WHO has developed BMI classification aimed for international use. Weight classification based on BMI is shown in Table 1 [13]. Accordingly, the Body mass index (BMI) was measured by multiplying the weight of each participant by their height (weight $/$ height $^{2}$ in $\mathrm{kg} / \mathrm{m}^{2}$ ). Obesity is defined as $\mathrm{BMI} \geq 30 \mathrm{~kg} / \mathrm{m}^{2}$. To calculate the body weight, the subjects were asked to put on the clothes provided by the center, the weight of which was reduced from the total body weight. Blood was drawn from an ante-cubital vein of each person while they were in a sitting position. A tourniquet was closed for less than 1 minute. White blood cells (WBCs) in a blood sample which was collected in tube with tripotassium EDTA tubes were counted by an automatic blood counter after two hours of vain puncture.

Table 1. Obesity and Overweight Indices ${ }^{\mathrm{a}}$

\begin{tabular}{lcc}
\hline Variables & BMI $\left(\mathbf{k g} / \mathbf{m}^{2}\right)$ & Obesity Class \\
\hline Underweight & $<18.5$ & \\
Normal & $18.5-24.9$ & \\
Overweight & $25.0-29.9$ & increased \\
Obesity & $30.0-34.9$ & high \\
& $35.0-39.9$ & very high \\
\hline Extreme Obesity- & $40.0+$ & extremely high \\
\hline
\end{tabular}

${ }^{\mathrm{a}}$ National heart, lung, and blood institute (NIH) [14].

A complete blood profile including WBC and Platelet counts was provided by an automated cell counter. In order to rule out any infection or underlying hematologic disorder, exclusion criteria were considered as people who have WBC count $\left(<3,800\right.$ or $>15,000$ cells $\left./ \mathrm{mm}^{3}\right)$, and platelets more than 500,000 cells $/ \mathrm{mm}^{3}$ [15].

Reliability estimates fall between 0.95 and 1.00. To compare platelet counts and WBC levels in overweight and obese groups with those in the control group a general linear model with post hoc Scheffe comparisons were run. T- test was used to check the significance of differences in the platelets count in obese and non-obese subjects. Analysis of variance (ANOVA) was run to estimate the association between BMI and platelet count after adjusting for age differences. Because of gender differences in baseline platelet counts. It was decided to analyze the data for males and females separately. Statistical package for social science (SPSS) version 16 was used to do the analyses. The descriptive Statistics included mean and standard deviation (SD). To measure the strength of association between BMI, WBC, and waist circumference, Pearson's correlation was used. The significance level for all the analyses was set at $\mathrm{P}<0.05$.

The study included 486 Iranian subjects (232 women and 254 men) with an average age of $34.75 \pm 8.1$ years. Overall, $48.4 \%$ were normal weight, $31.7 \%$ were overweight, $11.4 \%$ were obese and $0.8 \%$ were morbidly obese, and $47.6 \%$ were abdominal obese. Table 2 shows the main features of the study group. As the shows, shows, the WBC count was significantly higher in the obese group than it was in the control group (10.62 vs 6.17; $\mathrm{P}<0.001$ ). WBC was correlated with BMI in the obese group $(\mathrm{P}<0.05)$.

Table 2. The Features of the Study Groups $(n=486)$

\begin{tabular}{lcc}
\hline Variables & Men $(\mathbf{n}=\mathbf{2 3 2})$ & Women $(\mathbf{n}=\mathbf{2 5 4})$ \\
\hline Age, $\mathbf{y}$ & $33.5 \pm 8.2$ & $36.01 \pm 8.06$ \\
\hline $\mathbf{B M I}, \mathbf{~ k g} / \mathbf{m}^{\mathbf{2}}$ & $24.6 \pm 3.6$ & $25.7 \pm 4.9$ \\
$\mathbf{B m i}>\mathbf{3 0}, \%$ & 7.6 & 15.7 \\
\hline Waist circumference, $\mathbf{c m}$ & $1.04 \pm 0.5$ & $89.3 \pm 10.2$ \\
\hline Wbc & $6.78 \pm 1.9$ & $7.3 \pm 1.77$ \\
\hline Neutrophil & $62.5 \pm 7.2$ & $57.3 \pm 7.6$ \\
\hline Eosinophil & $1.88 \pm 0.9$ & $2.5 \pm 1.3$ \\
\hline Lymphocyte & $34.7 \pm 6.4$ & $38.2 \pm 6.9$ \\
\hline Monocyte & $2.91 \pm 1.5$ & $3.8 \pm 6$ \\
\hline PLT & $258.4 \pm 50.9$ & $233.7 \pm 43.8$ \\
\hline
\end{tabular}

Overall, $49.7 \%$ of men and $50.1 \%$ of women had normal weight while, $32.7 \%$ of men and $34.5 \%$ of female were overweight, and $15.7 \%$ of men and 0.8 of women were morbidly obese. Moreover $47.21 \%$ of women and $12.9 \%$ of men suffered from abdominal obesity.

Our data showed that the number of white blood cells was higher in individuals with high waist circumference) in female $(\mathrm{P}<0.015)$ and in men $(\mathrm{P}<0.001)$. Proportionate to BMI, platelet counts showed an increased in both gender. However, only in women, the number of platelets was significantly high in overweight $(\mathrm{P}=0.005)$, and obesity $(\mathrm{P}<0.0001)$, totally. The number of platelets was high and no significance difference was observed between the obese groups and the number of platelets compared to the 
Table 3. Platelet, and WBC Count, by Central Obesity ${ }^{\mathrm{a}, \mathrm{b}}$

\begin{tabular}{|c|c|c|c|c|}
\hline \multirow[t]{2}{*}{ Variables } & \multicolumn{2}{|c|}{$\operatorname{Men}(n=254)$} & \multicolumn{2}{|c|}{ Women $(n=232)$} \\
\hline & $\begin{array}{l}\text { Normal body fat distribution without } \\
\text { central obesity }(n=221)\end{array}$ & Central body fat distribution $(n=33)$ & $\begin{array}{l}\text { Normal body fat distribution without } \\
\text { central obesity }(n=123)\end{array}$ & Central body fat distribution $(n=109)$ \\
\hline Platelet count, $\times 10^{9} / \mathrm{L}$ ) & $263 \pm 45$ & $302 \pm 41^{\mathrm{C}}$ & $275 \pm 48$ & $296 \pm 55^{\mathrm{c}}$ \\
\hline White blood cells, $\times 1000$ counts & $5.7 \pm 4$ & $8.5 \pm 3^{c}$ & $6.3 \pm 6$ & $7.1 \pm 3^{c}$ \\
\hline
\end{tabular}

Table 4. Platelet, and WBC Count, by BMI Rate

\begin{tabular}{|c|c|c|c|c|c|c|}
\hline \multirow[t]{2}{*}{ Variables } & \multicolumn{3}{|c|}{$\operatorname{Men}(n=254)$} & \multicolumn{3}{|c|}{ Women $(n=232)$} \\
\hline & Normal weight $(\mathbf{n}=126)$ & Overweight $(\mathrm{n}=83)$ & Obese $(n=40)$ & Normal weight $(n=117)$ & Overweight $(\mathbf{n}=\mathbf{8 0})$ & Obese $(n=2)$ \\
\hline Platelet count, $\times 10^{9} / \mathrm{L}$ & $242 \pm 24$ & $248 \pm 26$ & $278 \pm 32$ & $251 \pm 36$ & $265 \pm 28^{\mathrm{C}}$ & $294 \pm 22^{\mathrm{C}}$ \\
\hline White blood cells, $\times 1000$ counts & $6.7 \pm 6$ & $7.1 \pm 2$ & $8.3 \pm 3^{C}$ & $6.5 \pm 3$ & $8.4 \pm 3^{\mathrm{b}}$ & $9.8 \pm 2^{\mathrm{C}}$ \\
\hline
\end{tabular}

${ }_{\mathrm{P}}$ Values derived from one-way ANOVA that evaluated the association between general obesity and several characteristics of the participants, after adjusting for age.

$\mathrm{b}_{\mathrm{P}}<0.05$ for the comparisons between overweight or obese vs. normal weight objects.

${ }^{c_{P}}<0.01$ for the comparisons between overweight or obese vs, normal weight objects.

normal weight subgroup after adjustment for age. With ANOVA, the number of platelets was always associated with $\mathrm{BMI}$ in women after adjustment for age $(\mathrm{P}=0.013)$. In a stepwise regression analysis (age, sex and BMI change were the model variables), the change in BMI was the only predictor of the change in WBC count. Also a significant correlation was found between waist circumference and platelet counts $(\mathrm{P}<0.0001)$ in both genders. Although the observed correlation was attenuated, it seemed to remain constant.

\section{Discussion}

The results of this study showed that although the number of platelets was high, there were no significant differences between obese and overweight subjects in the number of platelets compared to the subgroup of normal weight after adjustment for age in men. The number of platelets increased with BMI in both genders. But, only in women, the number of platelets was significantly high in obese and overweight subjects. The association between obesity related diseases has been documented in previous studies.

Charles et al. (2007), [15] for example reported that increase in tertiles of abdominal height would significantly be associated with an increase in the mean number of platelets in women, but no association was observed in men. Other studies have shown that the number of platelets would be significantly higher in participants who were resistance to insulin as compared to those who were sensitive to insulin [16].
We found a significant trend in the number of WBCs by increasing the waist circumference, without significant difference in terms of gender. The most consistent association was found between the number of white blood cells and the measurements of generalized and abdominal obesity, namely BMI and circumference of the waist. Also Womack et al. (2007) [17] found; there is strong evidence of an association between obesity and the white blood cells count increases in a female population. Studies have found that, there is some sort of association between the increased number of immune cells and obesity as a result of a chronic inflammatory condition which is created by an increase in the production of cytokines by adipose tissue. It has also been show that obesity is associated with low-grade subclinical and smoldering inflammation $[18,19]$. The health effects of low-grade systemic inflammation in healthy adults have shown an increased risk of cardiovascular disease and diabetes mellitus [20]. In support of previous findings, the positive associations between the number of cells and obesity have been reported in a number of cross sectional studies [15, 21]. For example, Herishanu et al. study [22] found that from among several factors responsible for persistent leukocytosis, such as smoking, myeloproliferative and lymphoproliferative disease, obesity would be the only identified cause.

Another study [23] found, higher rate of inflammatory markers, including a 17\% higher WBC count in participants with a central obesity as compared with those whose body fat was distributed normally. Nevertheless, in another study [15] it was shown that obesity would not be associated with the number of white blood cells without metabolic syndrome is not observed, but the metabolic 
syndrome was associated to a larger number of white blood cells in obese and non-obese subjects [15].

Considerable efforts have been made to understand the underlying biology in order to identify risk factors for cardiovascular disease. BMI and waist circumference are identified as a risk factor for coronary artery disease [24]. In addition, the increase in leukocytes associated with obesity is clinically important because granulocytes and monocytes can release some substances such as free radicals and proteolytic enzymes into the blood which are of potentially harm to the health [15].

It is important to understand the association between the number of white blood cells and CHD risk factors for the potential use of the number of white blood cells as a prognostic indicator of coronary artery disease. As far most people one or more risk factors for CHD or a metabolic syndrome cluster are present, it may not be wise to take a just associated components into account. Although the number of white blood cells still is one of the most common tests used to diagnose disease, it seems we should start to consider it as a good predictor of a disease as well $[25,26]$. Investigation of its association with platelet count revealed a statistically significant correlation between BMI and waist circumference with indices of platelet count. This study had several strengths. In addition to population size, other anthropometric factors were checked used to assess obesity, including some central obesity measures that are not commonly used in epidemiological studies. It seems that BMI would not be an ideal index of obesity in that. It can be affected by a greater muscle mass as well. Among the many anthropometric indices of obesity, it has been shown that measurements of central adiposity (e.g., waist circumference, waist-to-hip ratio, height-to-height ratio and abdominal height) are more strongly associated with several diseases or poor health that of the BMI in both genders [27, 28].

The present study suffered from some limitations. The cross sectional nature of the study is one of the main limitations, which makes it difficult to determine the causality with respect to observed relationships. In addition, as physical activity can also change the number of platelets proportional to the number of platelets and the number of leukocytes, C-reactive protein, fibrinogen, blood viscosity, factor VIII and IX, von Willebrand factor, dimer D of fibrin and the tissue plasminogen activator antigen [29].

It is likely that physical activity will affects the results; moreover, although efforts were to adjust some important risk factors, other potential confounders could have existed things such as depression or individuals usually consuming a diet high in fish have suppressed the number of platelets that we could not take into account. It is suggested that the relationship of obesity with other factors in the immune system, such as the sequence of C-reactive protein and (IL) -6 be studied [30]. Finally, it is suggested that studies on the relationship between the number of white blood cells and platelets count, and the distribution of abdominal fat in obese men and women, based on direct measurements of subcutaneous and visceral fat be performed.

\section{Acknowledgments}

Leila Jamshidi is writer and corresponding author also the data analysis and interpretation performed by Asghar Seif. Code research: 51711930422001. The authors would like to thank the Research Deputy of Hamedan branch of Islamic Azad University, Hamedan, Iran.

\section{Footnotes}

Conflict of interest: The authors declare no conflict of interest.

Funding/Support: Hamedan branch, Islamic Azad University.

\section{References}

1. World Health Organization. . 2008-2013 action plans for the global strategy for the prevention and control of non-communicable diseases 2008. Available from: http://www.who.int/nmh/publications/ 9789241597418/en/8T.

2. Expert Panel on Detection E, Treatment of High Blood Cholesterol in A. Executive Summary of The Third Report of The National Cholesterol Education Program (NCEP) Expert Panel on Detection, Evaluation, And Treatment of High Blood Cholesterol In Adults (Adult Treatment Panel III).JAMA. 2001;285(19):2486-97. [PubMed: 11368702].

3. Jamshidi L, Seif A, Vazinigheysar H. Comparison of indicators of metabolic syndrome in iranian smokers. Zahedan J Res Med Sci. 2014;16(1):55-8.

4. Health topics, cardiovascular diseases 2016. [cited Feb]. Available from: http://www.who.int/topics/cardiovascular_diseases/en/.

5. Available at: . Accessed ruary 2 . Cardiovascular diseases (CVDs) 2016. [cited Feb]. Available from: http://www.who.int/mediacentre/ factsheets/fs317/en/.

6. Sabatine MS, Morrow DA, Cannon CP, Murphy SA, Demopoulos LA, DiBattiste PM, et al. Relationship between baseline white blood cell count and degree of coronary artery disease and mortality in patients with acute coronary syndromes: a TACTICS-TIMI 18 (Treat Angina with Aggrastat and determine Cost of Therapy with an Invasive or Conservative Strategy- Thrombolysis in Myocardial Infarction 18 trial)substudy. J Am Coll Cardiol. 2002;40(10):1761-8. doi: 10.1016/S0735-1097(02)02484-1. [PubMed: 12446059].

7. Kannel WB, Anderson K, Wilson PW. White blood cell count and cardiovascular disease. Insights from the Framingham Study. JAMA. 1992;267(9):1253-6. doi: 10.1001/jama.267.9.1253. [PubMed:1538564].

8. Brown DW, Giles WH, Croft JB. White blood cell count: an independent predictor of coronary heart disease mortality among a national cohort. J Clin Epidemiol. 2001;54(3):316-22. doi: 10.1016/S08954356(00)00296-1. [PubMed: 11223329]. 
9. Bastien M, Poirier P, Lemieux I, Despres JP. Overview of epidemiology and contribution of obesity to cardiovascular disease. Prog Cardiovasc Dis. 2014;56(4):369-81. doi: 10.1016/j.pcad.2013.10.016. [PubMed: 24438728].

10. Obesity and overweight 2016. [cited Feb]. Available from: http://www. who.int/mediacentre/factsheets/fs311/en/.

11. Coban E, Ozdogan M, Yazicioglu G, Akcit F. The mean platelet volume in patients with obesity. Int J Clin Pract. 2005;59(8):981-2. doi: 10.1111/j.1742-1241.2005.00500.x. [PubMed: 16033624].

12. Hadaegh F, Azizi F. Effect of Weight Change on Incident of Metabolic Syndrome and its Components According to Iranian Waist Circumference and NHLBI:TLGS. Iranian Journal of Endocrinology and Metabolism. 2010;12(2):116-30.

13. Temple NJ, Steyn N. Community nutrition for developing countries. Canada: Athabasca University Press and UNISA Press; 2016.

14. The National Heart LABI(. Classification of overweight and obesity by BMI, waist circumference, and Associated Disease Risks Available from: https://www.nhlbi.nih.gov/health/educational/lose_wt/BMI/ bmi_dis.htm.

15. Charles LE, Fekedulegn D, McCall T, Burchfiel CM, Andrew ME, Violanti JM. Obesity, white blood cell counts, and platelet counts among police officers. Obesity (Silver Spring). 2007;15(11):2846-54. doi: 10.1038/oby.2007.338. [PubMed: 18070777].

16. Chen LK, Lin MH, Chen ZJ, Hwang SJ, Chiou ST. Association of insulin resistance and hematologic parameters: study of a middleaged and elderly Chinese population in Taiwan. J Chin Med Assoc. 2006;69(6):248-53. doi: 10.1016/S1726-4901(09)70251-5. [PubMed: 16863009].

17. Womack J, Tien PC, Feldman J, Shin JH, Fennie K, Anastos K, et al. Obesity and immune cell counts in women. Metabolism. 2007;56(7):9981004. doi: 10.1016/j.metabol.2007.03.008. [PubMed: 17570264].

18. Samocha-Bonet D, Justo D, Rogowski O, Saar N, Abu-Abeid S, Shenkerman G, et al. Platelet counts and platelet activation markers in obese subjects. Mediators Inflamm. 2008;2008:834153. doi: 10.1155/2008/834153. [PubMed: 18385810].

19. Yudkin JS, Kumari M, Humphries SE, Mohamed-Ali V. Inflammation, obesity, stress and coronary heart disease: is interleukin-6 the link?. Atherosclerosis. 2000;148(2):209-14. [PubMed: 10657556].

20. Visser M, Bouter LM, McQuillan GM, Wener MH, Harris TB. Lowgrade systemic inflammation in overweight children. Pediatrics. 2001;107(1):E13. doi: 10.1542/peds.107.1.e13. [PubMed: 11134477].
21. Dixon JB, O'Brien PE. Obesity and the white blood cell count: changes with sustained weight loss. Obes Surg. 2006;16(3):251-7. doi 10.1381/096089206776116453. [PubMed: 16545154].

22. Herishanu Y, Rogowski O, Polliack A, Marilus R. Leukocytosis in obese individuals: possible link in patients with unexplained persistent neutrophilia. Eur J Haematol. 2006;76(6):516-20. doi: 10.1111/j.16000609.2006.00658.x. [PubMed: 16696775].

23. Panagiotakos DB, Pitsavos C, Yannakoulia M, Chrysohoou C, Stefanadis $C$. The implication of obesity and central fat on markers of chronic inflammation: The ATTICA study. Atherosclerosis. 2005;183(2):308-15. doi: 10.1016/j.atherosclerosis.2005.03.010. [PubMed: 16285994].

24. Kelishadi R, Hashemipour M, Ashtijou P, Mirmoghtadaee P, Poursafa P, Khavarian N, et al. Association of cell blood counts and cardiometabolic risk factors among young obese children. Saudi Med J. 2010;31(4):406-12. [PubMed: 20383418].

25. Karino S, Willcox BJ, Fong K, Lo S, Abbott R, Masaki KH. Total and differential white blood cell counts predict eight-year incident coronary heart disease in elderly Japanese-American men: the Honolulu Heart Program. Atherosclerosis. 2015;238(2):153-8. doi: 10.1016/j.atherosclerosis.2014.12.003. [PubMed: 25514532]

26. Nakanishi N, Suzuki K, Tatara K. White blood cell count and clustered features of metabolic syndrome in Japanese male office workers. Occup Med (Lond). 2002;52(4):213-8. doi: 10.1093/occmed/52.4.213. [PubMed: 12091587].

27. Hadaegh F, Zabetian A, Harati H, Azizi F. Waist/height ratio as a bet ter predictor of type 2 diabetes compared to body mass index in Tehranian adult men-a 3.6-year prospective study. Exp Clin Endocrinol Diabetes. 2006;114(6):310-5. doi: 10.1055/s-2006-924123. [PubMed: 16868890]

28. Meisinger C, Doring A, Thorand B, Heier M, Lowel H. Body fat distribution and risk of type 2 diabetes in the general population: are there differences between men and women? The MONICA/KORA Augsburg cohort study. Am J Clin Nutr. 2006;84(3):483-9. [PubMed: 16960160].

29. Jesri A, Okonofua EC, Egan BM. Platelet and white blood cell counts are elevated in patients with the metabolic syndrome. JClin Hypertens (Greenwich). 2005;7(12):705-11. doi: 10.1111/j.1524-6175.2005.04809.x. [PubMed: 16330892] quiz 712-3.

30. Hojjatoleslami S, Jamshidi L. Relationship between C-reactive protein and obesity in adults. Zahedan J Res Med Sci. 2016;18(5):6662. doi: 10.17795/zjrms-6662. 